\title{
8. PREVENTION OF HEART DISEASES BY AYURVEDA
}

Author:- Dr.Mrs.Pallavi Abhijit Gune, Lecturer, Department of Rognidan, Yashwant Ayu. College P.G.T.\&R.C. Kodoli,

Co Author - Dr. Girbide S.G, Professor, Department of Rognidan, Yashwant Ayurvedic College, PGT \& RC, Kodoli,Email-drgirbide@gmail.com

\section{Abstract-}

Heart disease is commonly known as Coronary Artery Disease (CAD) .To treat CAD modern science uses medication as well as surgical intervention like Angioplasty \& CABG. But there is no any medication to prevent or rehabilitate this disease in modern science. Research proved life style modification plays definitive role in prevention of CAD. With the help of Ayurveda, prevention and rehabilitation of Hridrog can be done by Trisutri management . (Diet, Exercise \& Stress management)

\section{Index Terms-}

Angina Pectoris, Coronary Artery Disease (CAD),Diet,Exercise Hridrog, Stress management,Trisutri.

\section{Introduction-}

In Ayurveda Hridrog is considered as Kashtasadhya Vyadhi i.e. difficult to cure. As per modern \& speedy life style incidences of Hridrog (Heart Diseases) are increasing. Heart disease is commonly known as Coronary Artery Disease (CAD) .To treat CAD modern science uses medication as well as surgical intervention like Angioplasty \& CABG. But there is no any medication to prevent or rehabilitate this disease in modern science. Research proved life style modification plays definitive role in prevention of CAD. With the help of Ayurveda , prevention and rehabilitation of Hridrog can be done by Trisutri management . (Diet, Exercise \& Stress management)

\section{AIM of the project -}

To observe the effect of Trisutri management in Hridrog (IHD \& Angina) patients.

\section{Materials and Methods -}

2.1 - To detect patients with Angina, we used the questionnaire of London school of Cardiology and observed the preventive effect.

2.2 - We observed rehabilitation effect in IHD patients.

2.3 - We selected the patients, who are under observation of cardiologist.

2.4 - Diet charts - To lower cholesterol \& less lipids, green leafy vegetables, salads (onions, garlic, carrots, tomato, cucumber etc) fruits, toned milk. Phulakas, Sprouts - twice in week, Cereals, rice (Bharjit shali), in case of non vegetarian diet - once in week allowed only Less spicy \& oily fishes \& chicken. Egg without yellow yolk. Restricted Sugar \& salty diet. Avoid saturated fats, avoid Bakery products, fermented food products, junk \& fast food \& canned food products. To restrict Tea $\&$ coffee.

2.5 - Totally avoid Alcohol, tobacco in any form \& smoking.

2.6 - Exercises - Breathing exercise - Deep breath (Anulom \& Vilom - Pranayam), Stretching \& aerobic exercise \& avoid unaerobic exercise. Walking in fresh air (Morning walk) - not brisk walking or jogging. Progressive deep relaxation - Shavasana.

\section{7 - Stress management -}

Prarthana, Meditation, (Omkar stavan), free mind meditation, positive thinking, Visualisation.

2.8 - Dinkram - Wake up time 6 O'clock, exercise \& meditation - up to 7.30am.

Relaxation up to 8.00 o'clock, then Breakfast - up to 8.20am. 


\section{Ayurlog: National Journal of Research in Ayurved Science}

A Web based quarterly online published peer reviewed National E-journal of Ayurveda.

Lunch time $12.30-01.00 \mathrm{pm}$. one fruit or fruit juice at $4.30-05.00 \mathrm{pm}$.

At $06.00 \mathrm{pm}$ stretching, walking \& positive thinking and Dinner

At08.00pm. At 09.30pm Prarthana, Meditation \& visualisation

Followed by sleeping time at $10.00 \mathrm{pm}$.

\section{Selected patients divided in two groups -}

a> Newly diagnosed Angina Pectoris Patients.

b> Known case of IHD.

\section{1 - Selection criteria -}

Both groups of patients should non Diabetic, than 28 .

BMI of those patients should not more

No any major hormonal diseases.

\section{Questionnaire to diagnose Angina Pectoris -}

I] Have you ever had pain or discomfort in your chest ?

\section{Yes/No.}

If Yes, ask the next question .

II] Do you get it when you walk uphill or hurry?

Yes/No/ Never hurries or walks uphill.

III] Do you get it when you walk at an ordinary pace on the level?

Yes/No.

IV] What do you do if you get it while walking?

Stop or Slow down/Carry on.

V] If you stand still, what happens to it?

Relieved / Not relieved.

VI] How soon?

Ten minutes or less/More than ten minutes.

VII] Will you show me where it was?
Sternum (upper / Middle/lower)

Left anterior chest.

Left arm .

Other.

(Record all area mentioned)

VIII] Do you fill it any where else?

Yes/No

(If yes, record additional information)

'Angina' is defined as being present in subjects who answer as follows -

Q.1 - Yes,

Q.2 or 3 - Yes,

Q.4 - Stop or slow down.

Q.5 - Relieved.

Q.6 - 10 minutes or less,

Q7. - A. Sternum - Upper/Middle/Lower.

Or B. Left anterior chest and Left arm.

\section{Drug therapy should be continued as per} advice of cardiologist.

\section{Each patient was followed every weekly.}

Each patient had regular four visits.

If the patient having episodes during treatment period, is allowed to visit more than

Four times.

\section{OBSERVATIONS \& RESULTS -}

(After one month, followed by Trisutri Management)

7.1 - Relieved chest pain/ discomfort/ palpitation.

7.2 - Relieved dyspnoea.

7.3 - Increased capacity to walk.

7.4 - Regulation of bowel habits.

7.5 - Reduced stress levels - emotional stress as well as anxiety.

7.6 - Calm and quit sleep.

7.7 - Sense of well being. 


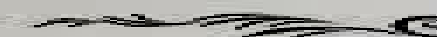

8. CONCLUSION management plays definitive role in prevention of HRIDROG, as all the patient get symptomatically relief. None of patient had chest pain or discomfort of chest or dyspnoea during the course of treatment, all of them had feeling of well being as the stress factor reduced. This effect can not be measured by any machine. Patients feels enthusiasm And their confidence increases.

9. ACKNOWLEDGEMENT - Thanks to all who help me in conducting this project. Special thanks to Dr. C.V.Patil sir, (Cardiologist) , Dr.Abhijit Gune , without his co operation this project is not possible.

\section{REFERRANCES -}

1. London school of Cardiology.

2. Dean Ornish's 'programme for reversing Heart Disease.

3. Dr. Ramnath Kapadia - Heart Disease 'New Direction'.

4. Indian Heart Journal. 